\title{
Synesthesia and the Color-light Keyboards
}

\author{
Kuo-Ying Lee
}

\begin{abstract}
The invention of a color-light keyboard combines the scientific and artistic domains in the performing arts. Based on the sound-color correspondence, the design of the color-light keyboard indicates a certain sound or a specific harmony in association with a particular color, shape, or colorful pattern. The correlation between visual image and sound is partially associated with the concept of synesthesia, refers tothe neurological condition of sensory fusionthat often appears in the musical composition. This study will investigate the revolution and development of the color-light keyboard in history, as well as the synesthetic perspectives concerning the originality and innovations of color-light keyboards made by different scholars.It will aim to explore the significanceof synesthetic behaviors in contemporary music performance presented bythe color-light keyboards, which pioneers the multimedia application in the performance.
\end{abstract} application.

\section{INTRODUCTION}

The utilization of multimedia tools is a growing trend in the field of performing arts, and the integration of an audio and visual experience enhances the artistic expression during a performance or anexhibition.Among many applications of the multimedia in music realms, the color-light keyboard has already received a considerable amount of scholarly attention as it increases the diversity and creativity of the music performance.Moreover,the synesthetic composers express the visual manifestation of musical sound through audience.Besides, the cooperation of the color-light keyboard and multimedia technology makes the perception of synesthetia more comprehensible to the non-synesthetes, which also enriches the artistic resources that are beneficial to the market of the performing arts.Over the centuries, the structure and equipment of the color-light keyboard have constantly developed and updated. The following paragraphs will discuss the originality, development and the innovation of the color-light keyboard.

\section{Inspiration from the Concept of Synesthesia}

There are many studies concerning the relationship between colors and sound. The most influential subject is the concept of "synesthesia", which means the union of senses, inspires the invention of the color-light keyboard.The perception of "synesthesia" was first mentioned in 1812 by the German physician Georg Sachs, depicting the simultaneous interaction between senses.The symptom of synesthesia is different from individual to individual. According to the English polymath Francis Galton

Revised Manuscript Received on December 15, 2020.

* Correspondence Author

Kuo-Ying Lee, College of Music, Zhaoqing University, Zhaoqing, China. Email: kuoyinglee@hotmail.com

(C) The Authors. Published by Blue Eyes Intelligence Engineering and Sciences Publication (BEIESP). This is an open access article under the CC BY-NC-ND license (http://creativecommons.org/licenses/by-nc-nd/4.0/)
Keywords: Synesthesia, Color-light Keyboards, Multimedia color-keyboards to interactively communicate with the

(1822-1911), who formulated complex tables and introduced the cross-modal associations of synesthesia to the public in his 1883 book,Inquiries into Human Faculty and Its Development,there are several types of synesthesia including number-color, form-color, date-color, and sound-color [1].Particularly, the most frequently discussed type of synesthetic examples in music literature is the sound-color synesthesia. The perception of synesthesia was first defined and summarized by Édouardo Cornaz (1825-1911) as the term of "hyperchromatopsia (perception of too many colors)"[2]. Cornaz's work became the first monograph on synesthesia[3]. Significantly, after then, psychologists have also shown a keen interest in the intersensory perception of both image and sound. The research on synesthesia reached a peak around the $20^{\text {th }}$ century.Influentially, the sensory fusion of synesthesia opens a new field of cross-modal studies, and the relevant researches persist to the present.

Although the first official account of "synesthetia" occurred in 1812, scientifically there is no credential model or reliable method to determine a synesthetic behavior as every synesthete has different perception, and it is difficult to examine the self-consistency. Historically, the relationship between visual arts and musical compositions has permeated literature before the "synesthesia" was proposed. The metaphorical expression of visual arts was adopted as a pedagogical means for learning the music. For example, the Medieval music theorist, Guido de Arezzo, developed the notable "Guaidonian hand" to help singers learn the songs.In his theory, each joint of the hand is representative of specific note within the hexachord system as a metaphor.

Moreover, sharing the common aesthetics of finding the balance in beauty, the compositional technique of contrapuntal music in the Renaissance period is similar to the counterpoint strategy in the visual art.In the late Baroque period, the term "Rococo" indicates a gorgeous ornamental expression, suggesting the rocaille style applicable to several fields in architecture, sculpture and music.Since the $18^{\text {th }}$ century, the multisensory context in musical compositions was developed to a certain extent due to the increasing studies in the subject of cross-modal associations.Furthermore, the philosophical and intellectual culture at the Enlightenment also reveals the exchange between visual art and music at the time. For example, John Locke (1632-1740) and Voltaire (1694-1778) respectively discussed the cross-modal association in the treatises Philosophical Theory of Color and Elements of the Philosophy of Newton.

In the $19^{\text {th }}$ and $20^{\text {th }}$ centuries, painters such as the French writer and critic Charles Baudelaire (1821-1867), the Russian visual-artist and composer Wassily Kandinsky (1866-1944), the French artist Robert Delaunay (1885-1941) and the synesthetic British artist David Hockney (b.1937), all set out to capture cross-modalideas, often involving musical association and affinity in their paintings.

Blue Eyes Intelligence Engineering

\& Sciences Publication

(C) Copyright: All rights reserved.

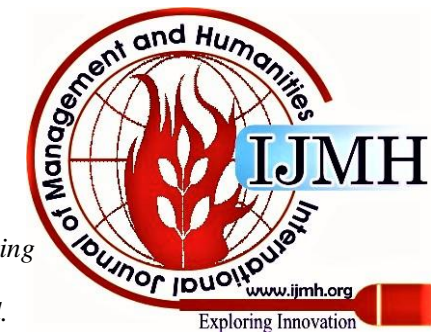




\section{Synesthesia and the Color-light Keyboards}

\section{Theories of Sound-Color Analogy}

Isaac Newton (1643-1727)declared in his treatiseOpticks (1704), that color is a sensation in the mind instead of an intrinsic property of the light itself. According to the statement in one of his 1675 letter, he used sonic wavelength to measure the visible spectrum of color, and established a theoretical proposition that associatesthe seven colors of red, orange, yellow, green, blue, indigo and violet with the seven basic degrees of the musical scale[4].Other than the scientific views of sound-color correspondences, scholars evaluate the sound-color relationship with philosophical and theosophical perspectives.

In contrast with Newton, Johan Wolfgang von Goethe (1749-1832) proposed a thesis concerning visual and aural sensations in his Zur Farbenlehre (Theory of Color), published in 1810[5].His radical point differs from Newton's physic discoveries, and Goethe enriched the philosophical perspectives of individual color. He also created a color wheel that involves the psychological aspects and emotional properties of each color, which leads to the further studies in human cognition for next decades, particularly,contributed by the philosophers and physics such as Arthur Schopenhauer, Kurt Gödel, and Ludwig Wittgenstein.

In 1888, the Russian philosopher Helena Petrovna (1831-1891) proposed in The Secret Doctrine, claiming that the theosophical ideas have a strong tie to the utilization of colors, and her theory inspired the well-known example of color-organ in the Prometheus symphony by the Russian composer Alexander Scriabin (1872-1915).Helena's theosophical points of views add the spiritual states to each color in corresponding to certain key. She utilizes the compound Sanskirt word "Kâma Rûpa", or "Wish of Form" to designate mental and physical desires as being linked with the color of red. The "Kâma Rûpa" also corresponds to "Do" on the musical scale. From Blavatsky's point of view, the color red contains all potentialities of Matter, and it is the start-point on the earth. Furthermore, the color green correlates to the idea of "Lower Manas", or "Self-Consciousness" which is equivalent to humankind's mind[6].

\section{THE APPLICATION OF COLOR-LIGHT KEYBOARDS}

The utilization of the color-light keyboards in compositions spans from the $18^{\text {th }}$ century to the present days, andthe scientific perspectivesof cross-modal experience in history are illustrated through the mechanical design of color-keyboards.With the explosive growth of innovative technology, the device and equipment of the color-light keyboard constantly update to present the sound-image correlations of the art works. Chronologically, the French mathematician Louis Bertrand Castel (1688-1757), the Scottish physicist Sir David Brewster (1781-1868), the American inventor Bainbridge Bishop (1837-1905), and the British artist Alexander Wallace Rimington (1854-1918)built up color-light keyboards and run into different technical challenges.

\section{REVOLUTION AND DEVELOPMENT OF COLOR-LIGHT KEYBOARDS}

\section{A. Color-light Keyboard in the $18^{\text {th }}$ century}

The first documented color-light keyboard was made by Louis Bertrand Castel (1688-1757), who proposed an ocular harpsichord in 1725 to illustrate his optical theories developed from Newton's basic seven-color system. He took advantage of the use of a candle-illuminated colored prism to demonstrate a systematic correlation of colors to pitches when certain keys were pressed by the organ.His instrument inspired the German composer George Philipp Telemann (1714-1736) to compose several pieces for it[7].The mechanical device of the instrument contains five octaves, sixty small colored glass panels, with each of them covered by a curtain. When the key was pressed, the curtain opened to make it sound. As a matter of the fact, Castel's original plan aimed to make an instrument comprised of twelve octaves with refractions of 144 colors through cylindrical candlescovered by colorful papers, which could be lightened and reflective when the flame was exposed.However,Castel'smost idealistic design was not fulfilled eventually due to the technical issue. Nevertheless, he initiated the first generation of the technological experimentation for the color-light keyboard[8].

\section{B. Color-light Keyboard in the $19^{\text {th }}$ century}

Later on, the Scottish scientist Sir David Brewster (1781-1868) further invented the kaleidoscope in 1817, and he tried to apply it as a basic form of the color organ, which reflected various colors from an object when it moved across the angular aperture.With the imaginary adoption of kaleidoscope's function, Brewster expected his color-light keyboard to display a symmetrical colorful pattern that makes a revolutionary visual effect.In 1877, the American scientist Bainbridge Bishop firstadopted the motor device to produce the simultaneous link between the sound and colors. With his innovation, the problem of lagging images behind the music in a process of performance is resolved.

\section{Color-light Keyboard in the $20^{\text {th }}$ century}

The application of the color-light keyboard in the $20^{\text {th }}$ century is promoted to a greater extent in the current multimedia age as the invention of the smart projector, LED displays, contact image sensors, image detectors, and cinema-quality surroundsound system enable the artists to explore a new form of visual art in connection with the innovative sonorous effect.Inspired by the Pop arts and the minimal arts, the contemporary color-light keyboards no longer focus on the music-sound analogies.Instead, the modern perspective of the synesthetic presentation emphasizes the visual and aural stimuli. Inventors such as James M Loring and Charles F Wilcox respectively built up their color-light keyboards in light of the modern aesthetic views [9].

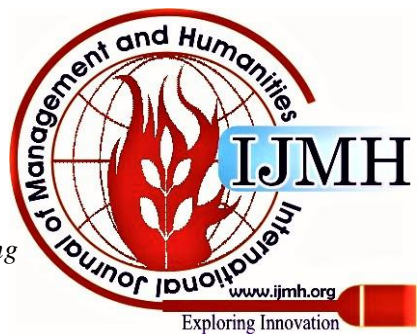




\section{COMPOSITIONS EMPLOYING THE COLOR-LIGHT KEYBOARDS}

One of the most important orchestral works characteristic of the color-light keyboard is Alexander Scriabin's fifth symphony, Prometheus, Poem of Fire, Op.60 (1908-1910). This composition contains the fusion of music, color, sound, light, and fire simultaneously together. The color keyboard in this piece was originally called clavier à lumières, also known as the Luce, which was a color organ designed specifically for the performance of Prometheus.It was played like a piano but projected just color-light on a screen in the concert hall, without any sound, acting as a colour-keyboard to project incandescent lights in a circle-of-fifths correspondence to the twelve key signatures.In the full score of Prometheus's second edition, Scriabin particularly annotated a supplementary stave designated for Luce, in which musical notes correspond to different colors determined by the composer. The color keyboard remarkably translated the notation into color-light rather than sound. The Luce part in Scriabin's Prometheus produces a visual portrayal, standing for the shifted root notes of the so-called Mystic chords, indicating the color changes and specific meanings.

The British artists Alexander Wallace Rimington (1854-1918) invented the Luce for Scriabin, and his instrument is over ten-feet high, comprised of five octaves, with the same function as an organ. The organ stops are used to adjust the brightness and the intensity of the colors. Overall his presentation was made by connecting the trackers from a series of lens diaphragm and filters for 14 arch lamps[10].In 1910, the physics technologist, Alexander Mozer helped Scriabin to build up an electronic keyboard in Prometheus, and he also enlarged the size of color organ. There are several distinct features in the Prometheus symphony. First, through the numerous color indications, the entire work presents the many culminations of human will, human consciousness, creativity, and humanity based on the theosophical ideas. Furthermore, the swift shift between Mystic chords utilized by Scriabin corresponds to Blavatsky's theory of interchangeable colors, which maintains that the extremity of one color leads to a visual contrast, and therefore to be a complementary color, which altogether unifies the spirits of the universe.

In 1922, the Hungarian composer Thomas Wilfred (1889-1968) improved the projection of colored light by using the potentiometer, which allows a performer to control the position of visual image during the performance.Thomas also created a term "Fablichtmusic" to define the genre of color-light keyboard compositions.One of his own notable works is title as A Fairy Tale of the Orient, Op.30, representing the colorful patterns derived from the colors of the Arabic decorative design [11].

The Zurich University of Arts and the Zurich Conservatory collaboratively accomplished an interdisciplinary project from 2003 to 2004 to illustrate a synesthetic performance through a color-light keyboardinvented by the pianist Natalia Sidler. This instrument has brighter colors in a higher register, and darker hues in the lower ones. Sidler's invention possessesthree modes. The first mode is turned on by the attached foreground sector to produce seven colors for seven tones.
The second mode changes the visual effect by adjusting the colors of the background behind the color keyboard. The third mode functions as a modification of the images, changing the design of colorful shape and pattern according to different timbres of the keyboard in association with the composer's personal synesthetic perceptions.

\section{CONCLUSION}

The historical survey of researches on synesthesia and the application of the color-light keyboard provide people a path to comprehend the cultural background of the art works.Moreover, the operation of a color-light keyboard in the performing arts creates more attractions that fit the current trend of the broadband network, by which an interactive communication between the artists and the audience is delivered.Thus, the integration of visual arts and music performance moves toward to a multi-sensory exhibition in a more interdisciplinary platform. For example, in 2019, the multimedia project "Van Gogh Alive"created a series of global art exhibitions of a 45-minute presentation, which displays Van Gogh's paintings through a combination of multichannel animation graphics, cinema-quality surroundsound system, and high-definition projectors. The masterpieces of Van Gogh are presented by the projectors, which project the pictures onto large screens, accompanied by classical music to provide the audience with a cross-modal experience.

Conclusively, the application of the color-light keyboard provides an innovative expression in the modern art. The development of the color-light keyboard hasa significant revolution which shows a technological progress in the history. It is my hope that this study will be a helpful source for the futuristic examination ofthecross-cultural perspectives of synesthesia as well as the relevant researches.

\section{REFERENCES}

1. Francis Galton,Inquiries into Human Faculty and Its Development $2^{\text {nd }}$ Edition, London: Macmillan Publishers Ltd., 1892.

2. Jörg Jewanski, Julia Simner, Sean A. Day, Jamie Ward, "The Development of a Scientific Understanding of Synesthesia from Early Case Studies (1849-1873)," Journal of the History of the Neurosciences,vol.20, pp.284-305.

3. Julia Simner, Edward Hubbard, Oxford Handbook of Synesthesia,Oxford: Oxford University Press, 2013.

4. IsaacNewton, Opticks. New York: Dover Publications Inc, 1997.

5. Johann Wolfgang vonGoethe,Theory of Color. Translated by Charles LockEastlake.London: John Murray, 1840.

6. Helena Blavatsky, The Secret Doctrine: The Synthesis of Science, Religion, and Philosophy (Volume 2).Cambridge: Cambridge University Press, 2011.

7. Bainbridge Bishop. A Souvenir of the Color Organ, with some Suggestions in Regard to the Soul of the Rainbow and Harmony of Light, New York: The De Vinne Press, 1893.

8. DonaldSchier, Louis Bertrand Castel, anti-Newtonian scientist.Iowa: The Torch Press,1941.

9. KennethPeacock, "Instruments to Perform Color-Music: Two Centuries ofTechnological Experimentation." Leonardo, vol.21,no.4, 1988, pp.397-406.

10. Eaglefield A. Hull, "A Great Russian Tone-Poet: Scriabin,” London: Kegan Paul, Trench, Trubner, and Co., LTD., 1916.

11. Daniel Conrad, "The Dichromaccord: Reinventing the Elusive ColorOrgan,”Leonardo,vol.32,no.5, 1999, pp.393-398.

Blue Eyes Intelligence Engineering \& Sciences Publication

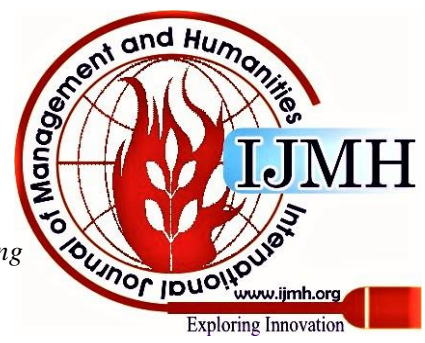




\section{AUTHORS PROFILE}

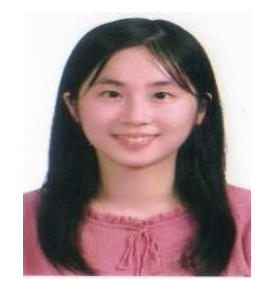

Kuo-Ying Leeholds, a doctoral degree from the University of North Texas in music, where she was awarded the Dean's Camerata scholarship. She earned her master's degree from the New England Conservatory (Boston, U.S.A). Ms. Lee was the first prize winner at Oberlin International Piano Competition (Ohio), assistant conductor at Amarillo Opera (Texas) and Vancouver Opera studio (Vancouver). Formerly she was teaching at National Chiao Tung University (Hsin-Chu, Taiwan) as an adjunct faculty member, and she is currently an associate professor at Zhaoqing University, College of Music in China. Lee's scholarly dissertations"An Examination of Innovations in Alexander Scriabin's Late Piano Works", "On the Inspiring Influence of Alexander Tcherepnin's Music Works on Jiang Wen-ye "had been published by University of North Texas and Shanghai Conservatory of Music Library. Her articles"A Comparative Study of Synesthetic Examples in Scriabin, Messiaen, and Ligeti's Selected Keyboard Works", "An Analysis of Symmetrical Structure in Piano Music by Olivier Messiaen", "Music Education under the Background of Civilization Initiative" had been submitted for publications with Vernon Press, Cambridge Scholars Publishing, and Flyccs Publishing.

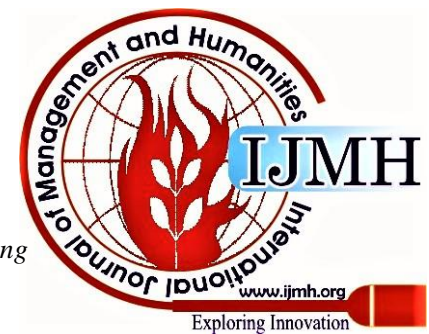

